\title{
THE SMECTITIC MINERALS IN A BENTONITE DEPOSIT \\ FROM MELO (URUGUAY)
}

L. CALARGE ${ }^{1,2}$, B. LANSON ${ }^{3, *}$, A. MEUNIER ${ }^{1}$ and M. L. FORMOSO ${ }^{2}$

1 - Université de Poitiers, Laboratoire Hydr'ASA, UMR 6532, 40 Av du Recteur Pineau, 86022 Poitiers Cedex, France

2 - Universidade Federal do Rio Grande do Sul, Instituto de Geociências, Av Bento

Gonçalves 9500, Porto Alegre, Brazil

3 - Environmental Geochemistry Group, LGIT, Maison des Géosciences, BP53, University of Grenoble - CNRS, 38041 Grenoble Cedex 9, France.

* Corresponding author - e-mail: Bruno.Lanson@obs.ujf-grenoble.fr 


\begin{abstract}
A nearly monomineralic $1.5 \mathrm{~m}$ thick bentonite bed sampled in Melo (Uruguay) appears to be a pure high-charge montmorillonite: $\left[\mathrm{Si}_{3.94} \mathrm{Al}_{0.06}\right]\left(\mathrm{Al}_{1.40} \mathrm{Fe}^{3+}{ }_{0.11} \mathrm{Ti}_{0.02} \mathrm{Mg}_{0.49} \mathrm{Mn}_{0.01}\right) \mathrm{O}_{10}$ $(\mathrm{OH})_{2} \mathrm{Na}_{0.01} \mathrm{~K}_{0.08} \mathrm{Ca}_{0.18}$. However, contrasting swelling behaviors have been evidenced by fitting the experimental X-ray diffraction patterns recorded on oriented preparations of the same sample in different saturation states. According to the expandability of the layers in the Ca-, $\mathrm{K}$ - and K-Ca-saturated (that is saturated first with $\mathrm{K}^{+}$and subsequently with $\mathrm{Ca}^{2+}$ ) states, three "layer types" were defined. Low-, intermediate-, and high-charge layers are fully, partly, and not expandable, respectively, after K-saturation. Collapse of high-charge layers is not reversible after subsequent Ca-saturation, most likely because of tetrahedral substitutions. These three different layer types are segregated in two distinct randomly interstratified mixedlayer phases. TSA and CEC are shown to depend on the interlayer cation composition.
\end{abstract}

KEYWORDS: Clay minerals, Bentonite, Montmorillonite, Mixed-layered minerals, Interstratification, Layer charge, Simulation, XRD 


\section{INTRODUCTION}

The structural features of smectites and illite-smectite mixed-layers (IS) from bentonite deposits have been largely studied and their expandable interlayers have consistently shown charge heterogeneities as revealed by potassium or alkylammonium saturation tests (Howard, 1981; Talibudeen \& Goulding, 1983; Cetin \& Huff, 1995). These heterogeneities are likely induced by contrasting chemical composition of octahedral and tetrahedral sheets from one layer to the other (Cuadros \& Altaner, 1998a). In turn, these heterogeneities may also influence the expandability and total surface area of expandable layer silicates as shown by Laird (1999). Specifically, the distribution of high- and low-charge layers in the stacking may lead to mixed-layered sequences involving more than two layer types (Foscolos \& Kodama, 1974; Cradwick \& Wilson, 1978). In addition to non-expandable layers (no ethylene glycol adsorption or 0EG: non expandable layers include illite and collapsed high-charge smectite layers when K-saturated), expandable layers may incorporate 2 or 1 ethylene glycol layers (2EG or 1EG, respectively). The existence of such layers having contrasting expandabilities is supported by the description of IS mixed-layered minerals (MLM) from diagenetic series using profile fitting of X-ray diffraction (XRD) patterns which most often can be satisfactorily achieved only using three-component systems (Drits et al., 1997; Sakharov et al., 1999).

To investigate the crystal structure of a smectite phase, and more specifically its layer charge heterogeneity, an almost monomineralic smectite was selected in a $1.5 \mathrm{~m}$ thick bentonite bed from Melo, Uruguay (Calarge et al., 2002). In this deposit, amounts of non clay minerals do not exceed $5 \%$ in weight. This smectite was shown to be a nearly pure montmorillonite whose layer charge is about -0.45 per $\mathrm{O}_{10}(\mathrm{OH})_{2}$. Layer charge heterogeneities were assessed using XRD patterns obtained from this sample in different 
saturation states, together with chemical composition, cation exchange capacity (CEC), total surface area data (TSA), and Fourier-transformed infrared (FTIR) spectroscopy.

\section{GEOLOGICAL SETTING AND SAMPLING}

The studied bentonite bed outcrops in a small quarry $50 \mathrm{~m}$ on the left side of the Melo to Montevideo road (Uruguay), $1 \mathrm{~km}$ aside from the $\mathrm{R} 7$ and $\mathrm{R} 6$ road intersection at $20 \mathrm{~km}$ from Melo (Fig. 1). It belongs to the Permian Yaguari Formation of the Paraná basin (Andreis et al., 1996). The outcropping rocks are fluviatile and aeolian sandstones interlaminated with pelitic deposits (red beds) typical of the lagunar environments induced by the sea regression during the late Permian (Andreis et al., 1996). During this period, the volcanic activity increased in the northern part of the Argentinian Patagonia, the maximum activity being attained during the Triassic and early Jurassic (Andreis et al., 1996). The magmatic eruptions were highly explosive leaving large silica-rich ash deposits (Axelrod, 1981). The sampled bentonite is a $1.5 \mathrm{~m}$ thick bed interlaminated in sandstone formations. The studied sample was taken from the middle of this massive pink soft rock bed to avoid contamination from surrounding sandstones.

\section{METHODS}

\section{Analytical procedures}

The bentonite sample was gently ground after drying at $60^{\circ} \mathrm{C}$. The powder was then dispersed in distilled water using an ultrasound probe. The $<1 \mu \mathrm{m}$ size fraction was separated using centrifugation and then Ca-, $\mathrm{K}-$, Li-, $\mathrm{Mg}$-, or $\mathrm{NH}_{4}$-saturated with $1 \mathrm{~N} \mathrm{CaCl}_{2}, \mathrm{KCl}, \mathrm{LiCl}$, 
$\mathrm{MgCl}_{2}$, or $\mathrm{CH}_{3} \mathrm{COONH}_{4}$, respectively. Suspensions were kept in contact with saline solutions for 4-12 hours at room temperature to ensure a complete cation exchange. After three replications of this procedure, the chloride in excess was rinsed out using ethylic alcohol until no precipitate formed with $\mathrm{AgNO}_{3}$. After $\mathrm{NH}_{4}$-saturation, the presence of $\mathrm{NH}_{4}{ }^{+}$in solution was checked using Nessler reactive. Part of the K-saturated samples was subsequently Caexchanged using the same experimental procedure (K-Ca treatment). The initial K-saturation aimed at irreversibly collapsing high-charge "expandable" layers, whereas the subsequent Caexchange was performed to totally re-expand layers having lower charges.

XRD patterns were collected from randomly oriented powders of natural, $\mathrm{Ca}-, \mathrm{K}-$ and $\mathrm{K}-$ Ca-saturated samples, as well as from oriented preparations of $\mathrm{Ca}-\mathrm{K}$ - and $\mathrm{K}-\mathrm{Ca}$-saturated samples in the air-dried (AD) and ethylene glycol solvated (EG) states. These patterns were recorded using a Siemens D500 diffractometer $(\mathrm{Cu} \mathrm{K \alpha}$ radiation generated at $40 \mathrm{kV}$ and $40 \mathrm{~mA}$ ), equipped with a SOCABIM DACO ${ }^{\circledR}$ data collection system and a Kevex PSI solid state detector. The analytical conditions for oriented preparations were $2-35^{\circ} 2 \theta$ as angular range, $0.025^{\circ} 2 \theta$ as scanning step size and $4 \mathrm{~s}$ as counting time. Powder XRD patterns were recorded in the same conditions except for angular range $\left(2-75^{\circ} 2 \theta\right)$ and counting time $(8 \mathrm{~s})$.

In addition, the octahedral charge of the sample was neutralized using the HoffmanKlemen treatment (Hoffman \& Klemen, 1950): Li-saturation and heating at $300^{\circ} \mathrm{C}$ for 12 hours. Untreated and treated samples were $\mathrm{NH}_{4}$-saturated to determine the respective contributions of octahedral and tetrahedral substitutions to the layer charge by comparing the surface areas of the IR $\mathrm{NH}_{4}^{+}$absorption band (Petit et al., 1998). IR spectra were recorded using a Nicolet 510 FTIR spectrometer in the transmission mode. The spectrometer was continuously purged with dry $\mathrm{CO}_{2}$-depleted air. Pressed pellets (4 $\mathrm{mg}$ of samples mixed with $300 \mathrm{mg}$ of $\mathrm{KBr}$ ) were analyzed with a $4 \mathrm{~cm}^{-1}$ resolution over the $4000-400 \mathrm{~cm}^{-1}$ range. 
The major elements were analyzed from a carbon-coated pressed pellet made from the $<1 \mu \mathrm{m}$ size fraction of the sample in its natural state and after $\mathrm{Ca}-\mathrm{K}$ - and $\mathrm{K}-\mathrm{Ca}$-saturation using a CAMECA SX50 microprobe equipped with wavelength dispersive spectrometers. The analytical conditions were $4-20 \mathrm{nA}, 15 \mathrm{kV}$, and a spot size diameter of $10 \mu \mathrm{m}$; the instrument was calibrated using natural silicates. An average composition was calculated for the natural sample from 50 analyses of the same pellet of the sample in its natural state. In addition, relative amounts of interlayer cations $(\mathrm{Ca}$, and $\mathrm{K})$ were calculated from 15 analyses made on the three saturated samples.

Cation exchange capacity (CEC) was measured on $\mathrm{Ca}-$, K-, and $\mathrm{K}-\mathrm{Ca}$ samples. These samples were first $\mathrm{Mg}$-saturated and subsequently $\mathrm{NH}_{4}$-exchanged using the experimental procedure described above. The amount of exchanged $\mathrm{Mg}$ was measured in solution using a Perkin-Elmer atomic absorption spectrometer (AAS). Measurements of total surface area (external + internal surfaces) were performed on the $\mathrm{Ca}-, \mathrm{K}$ - and $\mathrm{K}$-Ca samples using the adsorption of ethylene glycol monoethyl ether (EGME) according to the method recommended by Heilman et al. (1965). The total surface area (TSA) was calculated from the measured EGME mass divided by the monolayer EGME mass adsorbed per surface unit (3.77 $\left.10^{-4} \mathrm{~g} \mathrm{~m}^{-2}\right)$

\section{XRD pattern calculation}

Calculations of XRD patterns were performed using the MLM3C software developed by Plançon \& Drits (2000). Atomic coordinates for the different layer types were set as recommended by Moore \& Reynolds (1989), and the structural formula determined from chemical analyses (Table 1) was used to define the layer composition. The $\mathrm{d}_{001}$ of the different layer types was varied as needed within the limits given by Sato et al. (1992) to 
improve the quality of fit. Specifically, the following types of layers have been considered in the mixed-layering:

- AD and EG states: Collapsed smectite ( 0 water or EG layer: $0 \mathrm{~W}, 0 \mathrm{EG}), \mathrm{d}_{001} \sim 10.0 \AA$,

- AD state: 1 water layer smectite $(1 \mathrm{~W}), 12.1<\mathrm{d}_{001}<12.9 \AA$

2 water layer smectite $(2 \mathrm{~W}), 14.7<\mathrm{d}_{001}<15.5 \AA$

- EG state: $\quad 1 E G$ layer smectite, $12.7<\mathrm{d}_{001}<13.9 \AA$

2EG layer smectite, $16.5<\mathrm{d}_{001}<17.3 \AA$.

Among the other parameters which had to be adjusted in the trial-and-error fitting procedure, a special attention was paid to the proportions of each layer type, and to the coherent scattering domain size (N). The Reichweite parameter (Jagodzinski, 1949) for these three-component MLM was limited to $\mathrm{R}=0$ (random interstratification). Because only the main features of experimental XRD patterns were reproduced, precision on the proportion of the different layer types is about $\pm 10 \%$.

\section{RESULTS}

\section{Chemical composition}

The average structural formula calculated from the 50 microprobe analyses of the smectite in its natural state is that of a montmorillonite: [ $\left.\mathrm{Si}_{3.94} \mathrm{Al}_{0.06}\right]\left(\mathrm{Al}_{1.40} \mathrm{Fe}^{3+}{ }_{0.11} \mathrm{Ti}_{0.02} \mathrm{Mg}_{0.49}\right.$ $\left.\mathrm{Mn}_{0.01}\right) \mathrm{O}_{10}(\mathrm{OH})_{2} \mathrm{Na}_{0.01} \mathrm{~K}_{0.08} \mathrm{Ca}_{0.18}$ (Table 1a). The octahedral occupation (2.03) is typical of dioctahedral structures. The average layer charge is relatively high: 0.45 per $\mathrm{O}_{10}(\mathrm{OH})_{2}$, and is mostly compensated for by interlayer $\mathrm{Ca}^{2+}$ and $\mathrm{K}^{+}$cations in the natural state. These cations seem to be entirely exchangeable as shown by the interlayer composition determined from microprobe analyses after $\mathrm{Ca}$ - and $\mathrm{K}$-saturations: the $2 \mathrm{Ca} /(2 \mathrm{Ca}+\mathrm{K})$ ratios are 0.98 and 0.00 respectively (Table $1 b)$. After K-Ca treatment, this ratio has an intermediate value $(0.59)$, 
because some of the $\mathrm{K}^{+}$could not be exchanged any more after a complete K-saturation, which indicates the presence of high-charge layers (Howard, 1981).

CEC and TSA values depend on the saturating cations (Table 1b). CEC value decreases from 108.6 ceq. $\mathrm{kg}^{-1}$ for the Ca-saturated sample to 78.5 ceq. $\mathrm{kg}^{-1}$ for the $\mathrm{K}$-saturated one. Part of this decrease is related to the collapse of high-charge layers after K-saturation. However, because the CEC increases to 94.2 ceq. $\mathrm{kg}^{-1}$ after subsequent Ca-saturation, another part of the observed decrease is linked to the nature of the interlayer cation. TSA value decreases from $605.63 \mathrm{~m}^{2} \mathrm{~g}^{-1}$ for the Ca-saturated sample to $367.12 \mathrm{~m}^{2} \mathrm{~g}^{-1}$ for the K-saturated one to indicate that about $40 \%$ of the layers in K-saturated sample are not accessible to EGME. This is consistent with the interlayer $\mathrm{K}^{+}$cation effect depicted by Cuadros (1997) who described Ksaturated clays as MLM of one water layer and dehydrated interlayers. Only 5\% layers remain inaccessible to EGME after subsequent Ca-exchange $\left(577.33 \mathrm{~m}^{2} \mathrm{~g}^{-1}\right)$. Thus, according to TSA measurements, three types of layers can be distinguished: $60 \%$ are always accessible to EGME whatever the interlayer cation; among the remaining $40 \%$ layers, $35 \%$ are inaccessible only in this $\mathrm{K}$-saturated state, whereas 5\% remain inaccessible after subsequent $\mathrm{Ca}$-exchange.

\section{XRD patterns}

Powder XRD patterns. Together with small amounts of quartz, smectite is at large the major component of the bulk rock in its natural state (Fig. $2 \mathrm{a}$ ). The $\mathrm{d}_{060}$ spacing at $1.504 \AA$ confirms the dioctahedral character of the smectite. The high intensity of this peak indicates that the size of the coherent scattering domains is large in the a-b plane. The un-modulated asymmetrical $(20,13)$ band at $34-39^{\circ} 2 \theta \mathrm{Cu}-\mathrm{K} \alpha$ for the $\mathrm{Ca}$ - and $\mathrm{K}-\mathrm{Ca}$-saturated samples is typical of a fully turbostratic stacking mode (Mamy \& Gaultier, 1976; Reynolds, 1992). The contribution of high order $\mathrm{d}_{00}$ peaks in this angular range has been checked on oriented preparations and is reduced to weak modulations which become non-measurable on randomly 
oriented preparations. As a consequence, any change of the shape of this broad band is related to a modification of the stacking order. The K-saturated sample shows such a modulation (intense peak at $2.58 \AA$ and weak peak at about $2.47 \AA$ ), indicating a decreasing proportion of random stacking faults with increasing amounts of interlayer $\mathrm{K}^{+}$(Fig. 2b).

Oriented preparations of the Ca-saturated sample. The XRD patterns in the AD and EG states are typical of a nearly pure smectite (Fig. 3a,b) with almost harmonic series of peaks. However, the lack of strict harmonicity $\left(\mathrm{d}_{001} \neq \ell \cdot \mathrm{d}_{00_{\ell}}\right)$ indicates possible interstratification effects of layers having different thicknesses.

Oriented preparations of $K$ - and $K$-Ca-saturated samples. The XRD patterns of K-saturated samples in the $\mathrm{AD}$ and EG states exhibit a broad peak at 11.96 and $14.12 \AA$ respectively (Fig. 3). In the EG state, the shift of the $d_{001}$ value from $17.06 \AA$ for Ca-saturated samples to $14.12 \AA$ for the K-saturated one is due to the presence of 1 and/or 0EG layers in the stacking sequence. After K-Ca treatment in the EG state, the $\mathrm{d}_{001}$ shifts back from 14.12 to $16.96 \AA$ (Fig. 3d,f). Concomitantly, the (002), (003) and (005) peaks shift to 8.86, 5.56 and $3.37 \AA$ respectively and become more intense. Positions, and more especially their non-rationality, contrasting widths, and asymmetry of these peaks indicate the interstratification of several layer types with variable amounts of ethylene glycol. Summarizing, both AD and EG XRD patterns recorded for the three saturation states show that the peak sequences do not form a purely harmonic series indicating that this smectite behaves as a MLM.

Calculation of XRD pattern from oriented preparations. The experimental XRD patterns of Ca-, K- and K-Ca-saturated samples in the AD and EG states were compared to calculated ones using a trial-and-error method to reproduce the main features of the experimental traces over the 2 to $35^{\circ} 2 \theta \mathrm{Cu}-\mathrm{K} \alpha$ angular range. Even though the agreement between experimental and calculated patterns is not perfect, calculations may be considered satisfactory approximations (Fig. 3). 
For the Ca-saturated sample, no collapsed layers are detected in the AD or EG states. The two XRD patterns of this sample may be reproduced by using a unique MLM (MLM1) containing two different layer types. One may note in Table 2 that the proportion of layers with $1 \mathrm{EG}$ in the $\mathrm{EG}$ state corresponds to that of layers with $1 \mathrm{~W}$ in the $\mathrm{AD}$ state.

After K-saturation, part of the layers are collapsed to $10.0 \AA$. In addition, collapsed layers seem to form clusters as experimental patterns could only be reproduced assuming the presence of two MLM, one containing about $30 \%$ of collapsed layers (MLM1) whereas the other contains $80-90 \%$ of these 10.0 Å layers (MLM2). The expandable:collapsed layers ratio in the two MLM components, as well as their relative proportions are similar for K-, and KCa-saturated samples in both $\mathrm{AD}$ and EG states. However, in contrast to the results obtained for the Ca-saturated sample, the proportion of layers with 1EG in the EG state does not correspond systematically with that of layers with $1 \mathrm{~W}$ in the AD state. For the K-saturated sample, these two proportions are similar (55\% of $1 \mathrm{~W}$ layers and $60 \%$ of $1 \mathrm{EG}$ layers), but they differ significantly for the K-Ca-saturated sample (15\% of $1 \mathrm{~W}$ layers and $0 \%$ of $1 \mathrm{EG}$ layers).

\section{FTIR spectra}

The integrated intensity of the $\mathrm{NH}_{4}^{+} v_{4}$ absorption band at $1400 \mathrm{~cm}^{-1}$ was shown to be proportional to the quantity of $\mathrm{NH}_{4}{ }^{+}$ions exchanged for interlayer cations (Petit et al., 1998), that is $\mathrm{Ca}^{2+}$ in the present case. This quantity decreases drastically when the octahedral charge has been previously neutralized using the Hoffman-Klemen treatment (Fig. 4). This indicates that most of the layer charge originates from octahedral $\mathrm{R}^{2+}$ for $\mathrm{R}^{3+}$ substitutions with only a small part of the layer charge located in the tetrahedral sheet (Al for Si substitutions). According to the respective areas of the $1400 \mathrm{~cm}^{-1}$ bands, the tetrahedral charge is estimated to represent about $8 \%$ of the total layer charge. This value is similar although lower than the 
one obtained using the structural formula (13\%). As uncertainties in the surface area measurements of weak absorption bands are unavoidable, we think the tetrahedral charge calculated from the structural formula more accurate.

\section{DISCUSSION}

\section{Variation of expandability}

The number of expandable layers is much lower in K- and K-Ca-saturated samples than in the Ca-saturated samples in which expandable layers largely predominate. In addition, relative proportions of the different layer types are comparable in both $\mathrm{AD}$ and $\mathrm{EG}$ states for these two samples indicating that part of $\mathrm{K}^{+}$ions is irreversibly fixed during $\mathrm{K}$-saturation thus reducing the expandability. As expandability is known to depend on the layer charge (Malla \& Douglas, 1987; Sato et al., 1992; Laird, 1999), the differences between Ca-, K- and K-Casaturated samples observed here suggest that the layer charge is not similar for all smectite layers. If so, some properties like CEC or TSA would also vary as a function of the nature of interlayer cations.

For example, it is possible to study the relationships between crystal structure, physical (TSA, total amount of 2EG layers) and chemical (CEC) properties by using the contrasting amounts of interlayer $\mathrm{K}^{+}$ions in $\mathrm{Ca}-, \mathrm{K}$ - and $\mathrm{K}-\mathrm{Ca}$-saturated samples as a variable. From the linear relations shown in Fig. 5 it is possible to assume that the relative proportion of 2EG layers, TSA and CEC are interdependent parameters controlled by the amount of $\mathrm{K}^{+}$in the interlayers. The steady decrease of the relative proportion of $2 \mathrm{EG}$ layers with increasing content of $\mathrm{K}^{+}$indicates that these cations are preferentially adsorbed by some layers which then collapse to $1 \mathrm{EG}$ or $0 \mathrm{EG}$. Accordingly, in the K-saturated sample the TSA and CEC values are 40 and $30 \%$ lower, respectively, than the values measured for the Ca-saturated 
sample. However, it should be noted that whereas part of the $\mathrm{K}^{+}$cations is irreversibly fixed $(\sim 40 \%$ - Table 1$)$, in agreement with the observed irreversible collapse of smectite layers $(\sim$ $35 \%$ ), part of the CEC and most of the TSA are restored by subsequent Ca-saturation (K-Ca samples). This implies that CEC and TSA strongly depend on the nature of interlayer cation and not only on the amount of layer charge.

\section{Layer charge heterogeneity}

Malla \& Douglas (1987) showed that the layer charge scatters from 0.30 to 0.63 per $\mathrm{O}_{10}(\mathrm{OH})_{2}$ for fully expandable (2EG) and collapsed (0EG) smectite layers, respectively, in the K-saturated state. Using the detailed description of the layer swelling behavior coming from the trial-and-error fitting of experimental XRD profiles (Table 2) it is possible to refine the description made by these authors and to differentiate three different layer types, and to estimate their relative proportions:

1) Full expandability after K-saturation - Low charge: 2EG in both Ca- and K-saturated states $(\sim 15 \%)$;

2) Partial expandability after K-saturation - Intermediate charge: collapse from $2 \mathrm{EG}$ in Casaturated state to $1 \mathrm{EG}$ after K-saturation $(\sim 50 \%)$; these layers are fully expandable after subsequent Ca-saturation (K-Ca-saturation);

3) No expandability after K-saturation - High charge: collapse from 2EG in Ca-saturated state to $0 \mathrm{EG}$ in $\mathrm{K}$-saturated states $(\sim 35 \%)$; the collapse of these layers is not reversible after subsequent Ca-saturation.

From the 0.30 and 0.63 layer charges (per $\mathrm{O}_{10}(\mathrm{OH})_{2}$ ) defined by Malla \& Douglas (1987) for K-saturated 2EG and 0EG layers, respectively, it is possible to calculate that of the 1EG layers $\left(0.37\right.$ per $\left.\mathrm{O}_{10}(\mathrm{OH})_{2}=(0.45-(15 \% \times 0.30+35 \% \times 0.63)) / 50 \%\right)$ from the average layer charge $\left(0.45\right.$ per $\left.\mathrm{O}_{10}(\mathrm{OH})_{2}\right)$. On the other hand, from the average chemical composition 
(Table 1a) and the FTIR data (Fig. 4) which indicate that about $10 \%$ of the layer charge originates from the tetrahedral sheets, the average octahedral charge is 0.40 per $\mathrm{O}_{10}(\mathrm{OH})_{2}$.

It is then possible to hypothetically distribute layer charges between octahedral and tetrahedral sheets for the different layer types. For low- and intermediate-charge layers, the total layer charge $\left(0.30\right.$ and 0.37 per $\mathrm{O}_{10}(\mathrm{OH})_{2}$, respectively) is lower than the average octahedral charge, and likely originates only from octahedral substitutions. In turn, it is possible to estimate for high-charge layers the relative contributions of octahedral $(0.49$ per $\left.\mathrm{O}_{10}(\mathrm{OH})_{2}\right)$ and tetrahedral $\left(0.14\right.$ per $\left.\mathrm{O}_{10}(\mathrm{OH})_{2}\right)$ substitutions to the total layer charge. The former value is consistent with the results obtained by Calarge et al. (2002) using FTIR which showed no $\mathrm{Mg}-\mathrm{OH}-\mathrm{Mg}$ absorption bands. In addition, the presence of tetrahedral charge is assumed to favor the irreversible collapse of smectite layers after K-saturation.

\section{CONCLUSION}

The exceptional montmorillonite sampled in Melo (Uruguay) is composed of layers whose composition varies from low to high-charge smectite. This variation results from the heterogeneous distribution of tetrahedral charges in polarized 2:1 layers. In turn, these layers, which present contrasting swelling behaviors are stacked in two distinct mixed-layered structures. The first one contains mostly ( $80 \%)$ fully expandable (2EG) low-charge layers, whereas the second one contains mostly ( 80\%) high-charge layers which collapse irreversibly after K-saturation.

This layer charge heterogeneity, both at the layer and at the crystal scales, rises the problem for the definition of montmorillonite as a mineral phase, as it would make difficult (meaningless?) the measurement of thermodynamic parameters through dissolution or microcalorimetric experiments. From a theoretical point of view, the coexistence of two 
MLMs with different compositions means that thermodynamic conditions should be controlled along a tie-line until one of them disappears. In the present case, the diagenetic environment would likely destabilize the more expandable MLM1, and MLM2 should be considered as a precursor of illite-smectite MLMs.

\section{ACKNOWLEDGEMENTS}

Javier Cuadros and Boris A. Sakharov are thanked for reviewing the initial version of this article with great care and for their extremely pertinent suggestions. Anne-Marie Karpoff is thanked for her editorial assistance. Financial support has been provided by the CAPESCOFECUB program 349/01.

\section{REFERENCES}

Andreis R.R., Ferrando L. \& Herbst R. (1996) Terrenos Carboníferos y Pérmicos de la República Oriental del Uruguay. Pp. 309-343 in: El Sistema Pérmico en la República Argentina y en la República Oriental del Uruguay. Academia Nacional del Uruguay, Cordoba, Argentina.

Axelrod D.I. 1981. Role of volcanism in climate and evolution. Geological Society of America, Special Paper 185.

Calarge L., Meunier A. \& Formoso M.L.L. (2002) A bentonite bed in the Acegua (RS,Brazil) and Melo (Uruguay) areas: a highly crystallized montmorillonite. Journal of South American Earth Sciences, in press.

Cetin K. \& Huff W.D. (1995) Layer charge of the expandable component illite/smectite in Kbentonite as determined by alkylammonium ion exchange. Clays and Clay Minerals, $\mathbf{4 3 ,}$ $150-158$.

Cradwick P.D. \& Wilson M.J. (1978) Calculated X-ray diffraction curves for the interpretation of a three-component interstratified system. Clay Minerals, 13, 53-64.

Cuadros J. (1997) Interlayer cation effects on the hydration state of smectite. American Journal of Science, 297, 829-841. 
Cuadros J. \& Altaner S.P. (1998a) Characterization of mixed-layer illite-smectite from bentonite using microscopic, chemical and X-ray methods: Constraints on the smectiteto-illite transformation mechanism. American Mineralogist, 83, 762-774.

Drits V.A., Lindgreen H., Sakharov B.A. \& Salyn A.S. (1997) Sequence structure transformation of illite-smectite-vermiculite during diagenesis of Upper Jurassic shales, North Sea. Clay Minerals, 33, 351-371.

Foscolos A.E. \& Kodama H. (1974) Diagenesis of clay minerals from Cretaceous shales of north eastern British Columbia. Clays and Clay Minerals, 22, 319-335.

Heilman M.D., Carter D.L. \& Gonzalez C.L. (1965) The ethylene glycol monoethyl ether (EGME) technique for determining soil-surface area. Soil Science, 100, 409-413.

Hoffmann U. \& Klemen E. (1950) Loss of exchangeability of lithium ions in bentonite on heating. Zeitschrift für Anorganische und Allegemeine Chemie, 262, 95 -99

Howard J.J. (1981) Lithium and potassium saturation of illite/smectite clays from interlaminated shales and sandstones. Clays and Clay Minerals, 29, 136-142.

Jagodzinski H. (1949) Eindimensionale Fehlordnung in Kristallen und ihr Einfluss auf die Röntgeninterferenzen: I. Berechnung des Fehlordnungsgrades aus der Röntgenintensitaten. Acta Crystallographica, 2, 201-207.

Laird D.A. (1999) Layer charge influences on the hydration of expandable 2:1 phyllosilicates. Clays and Clay Minerals, 47, 630-636.

Malla P.B. \& Douglas L.A. (1987) Identification of expanding layer silicates: layer charge vs. expansion properties. Pp. 277-283 in: Proceedings of the International Clay Conference, Denver 1985 (L.G. Schultz, H. van Olphen \& F.A. Mumpton editors). Clay Minerals Society, Bloomington, Indiana.

Mamy J. \& Gaultier J.P. (1976) Les phénomènes de diffraction de rayonnements X et électroniques par les réseaux atomiques. Application à l'étude de l'ordre cristallin dans les minéraux argileux. II. Evolution structurale de la montmorillonite associée au phénomène de fixation irréversible du potassium. Annales Agronomiques, 27, 1-16.

Moore D.M. \& Reynolds R.C., Jr (1989) X-ray diffraction and the identification and analysis of clay minerals. Oxford University Press, Oxford \& New York.

Petit S., Righi D., Madejova J. \& Decarreau A. (1998) Layer charge estimation of smectites using infrared spectroscopy. Clay Minerals, 33, 579-591.

Plançon A. \& Drits V.A. (2000) Phase analysis of clays using an expert system and calculation programs for X-ray diffraction by two- and three-component mixed-layer minerals. Clays and Clay Minerals, 48, 57-62. 
Reynolds R.C., Jr. (1992) X-ray diffractions studies of illite/smectite from rocks, $<1 \mu \mathrm{m}$ randomly oriented powders, and $<1 \mu \mathrm{m}$ oriented powder aggregates: The absence of laboratory-induced artifacts. Clays and Clay Minerals, 40, 387-396.

Sakharov B.A., Lindgreen H., Salyn A.L. \& Drits V.A. (1999) Determination of illitesmectite structures using multispecimen X-ray diffraction profile fitting. Clays and Clay Minerals, 47, 555-566.

Sato T., Watanabe T. \& Otsuka R. (1992) Effects of layer charge, charge location, and energy change on expansion properties of dioctahedral smectites. Clays and Clay Minerals, $\mathbf{4 0}$, 103-113.

Talibudeen O. \& Goulding K.W.T. (1983) Charge heterogeneity in smectites. Clays and Clay Minerals, 31, 37-42. 


\section{FIGURE CAPTIONS}

Figure 1. Setting of the bentonite bed from Melo (Uruguay). The location of the outcrop is shown as a solid square.

Figure 2. Powder XRD patterns of Melo bentonite. $\mathrm{Qz}=$ quartz. a) Bulk rock in its natural state. b) $<1 \mu \mathrm{m}$ size fraction after Ca-, K-, and K-Ca-saturation. The 20, 13 band is shown to illustrate the contrasting degree of layer stacking disorder as a function of the interlayer cation.

Figure 3. XRD patterns of oriented preparations of the $<1 \mu \mathrm{m}$ size fraction after Ca-, K-, and K-Ca-saturation in the air dried (AD) and ethylene glycol (EG) solvated states. Experimental and calculated profiles are shown as crosses and solid lines, respectively. Peak positions determined on experimental XRD patterns are compared to those determined on calculated profiles. Calculated positions are given in parentheses. All parameters used for the calculation of XRD patterns are given in Table 2.

Figure 4. FTIR spectra showing the typical $v_{4}$ absorption band of $\mathrm{NH}_{4}^{+}$ions for $\mathrm{NH}_{4}^{+}-$ saturated samples. Untreated and Hoffman-Klemen treated samples are shown as solid and dashed lines, respectively.

Figure 5. Evolution of expandability (a), $\operatorname{CEC~(b),~and~TSA~(c)~as~a~function~of~the~interlayer~}$ cation composition expressed as $2 \mathrm{Ca} /(2 \mathrm{Ca}+\mathrm{K})$. Expandability is characterized by the relative proportion of 2EG layers (\%2EG). 


\section{TABLES}

\begin{tabular}{|c|c|c|c|c|c|c|c|c|c|}
\hline a) & $\mathrm{SiO}_{2}$ & $\mathrm{Al}_{2} \mathrm{O}_{3}$ & $\mathrm{Fe}_{2} \mathrm{O}_{3}$ & $\mathrm{TiO}_{2}$ & $\mathrm{MgO}$ & $\mathrm{MnO}$ & $\mathrm{CaO}$ & $\mathrm{K}_{2} \mathrm{O}$ & $\mathrm{Na}_{2} \mathrm{O}$ \\
\hline Oxide (\%) & 54.69 & 17.23 & 2.04 & 0.29 & 4.58 & 0.11 & 2.32 & 0.83 & 0.10 \\
\hline \multirow[t]{2}{*}{$\sigma( \pm)$} & 2.80 & 1.15 & 0.82 & 0.14 & 0.30 & 0.09 & 0.31 & 0.68 & 0.04 \\
\hline & $\mathrm{Si}$ & $\mathrm{Al}$ & $\mathrm{Fe}^{3+}$ & $\mathrm{Ti}$ & $\mathrm{Mg}$ & Mn & $\mathrm{Ca}$ & K & $\mathrm{Na}$ \\
\hline at. $\mathrm{O}_{10}(\mathrm{OH})_{2}$ & 3.94 & 1.46 & 0.11 & 0.02 & 0.49 & 0.01 & 0.18 & 0.08 & 0.01 \\
\hline \multicolumn{2}{|c|}{ b) Saturation } & \multicolumn{3}{|c|}{$\mathrm{CEC}\left(\right.$ ceq $\left.\mathrm{kg}^{-1}\right)$} & \multicolumn{2}{|c|}{$2 \mathrm{Ca} /(2 \mathrm{Ca}+\mathrm{K})$} & \multicolumn{3}{|c|}{ TSA $\left(\mathrm{m}^{2} \mathrm{~g}^{-1}\right)$} \\
\hline $\mathrm{Ca}$ & & \multicolumn{2}{|c|}{108.62} & & \multicolumn{2}{|c|}{0.98} & \multicolumn{3}{|c|}{605.63} \\
\hline $\mathrm{K}$ & & \multicolumn{2}{|c|}{78.46} & & \multicolumn{2}{|c|}{0} & \multicolumn{3}{|c|}{367.12} \\
\hline $\mathrm{K}-\mathrm{Ca}$ & & \multicolumn{2}{|c|}{94.24} & & \multicolumn{2}{|c|}{0.59} & \multicolumn{3}{|c|}{577.33} \\
\hline
\end{tabular}

Table 1. Chemical characteristics. a) Bulk chemical composition of the smectite in its natural state (average from 50 microprobe analyses) and structural formula calculated for $\mathrm{O}_{10}(\mathrm{OH})_{2}$. b) Cation exchange capacity (CEC) determined after Mg-exchange of the samples, average interlayer composition from 15 micropobe analyses $(2 \mathrm{Ca} /(2 \mathrm{Ca}+\mathrm{K})$ ratio) and total surface area (TSA) measured by EGME absorption for Ca-, K- and KCa-saturated samples. 


\begin{tabular}{|c|c|c|c|c|c|c|c|c|c|c|}
\hline a) & & & LM 1 & & & & & ILM 2 & & \\
\hline Saturation & $2 \mathrm{~W}$ & $1 \mathrm{~W}$ & $0 \mathrm{~W}$ & $\mathrm{~N}$ & $\mathrm{Ab}$. & $2 \mathrm{~W}$ & $1 \mathrm{~W}$ & 0W & $\mathrm{N}$ & $\mathrm{Ab}$. \\
\hline $\mathrm{Ca}$ & $\begin{array}{c}15.1 \AA \\
95 \%\end{array}$ & $\begin{array}{c}12.4 \AA \\
5 \%\end{array}$ & - & 6 & 1.00 & - & - & - & - & - \\
\hline K & $\begin{array}{c}15.0 \AA \\
5 \%\end{array}$ & $\begin{array}{c}12.4 \AA \\
55 \%\end{array}$ & $\begin{array}{c}10.0 \AA \\
40 \%\end{array}$ & 6 & 0.80 & - & $\begin{array}{c}12.6 \AA \\
20 \%\end{array}$ & $\begin{array}{c}10.0 \AA \\
80 \%\end{array}$ & 5 & 0.20 \\
\hline $\mathrm{K}-\mathrm{Ca}$ & $\begin{array}{c}15.0 \AA \\
55 \%\end{array}$ & $\begin{array}{c}12.8 \AA \\
15 \%\end{array}$ & $\begin{array}{c}10.0 \AA \\
30 \%\end{array}$ & 6 & 0.80 & $\begin{array}{c}15.0 \AA \\
10 \%\end{array}$ & - & $\begin{array}{c}10.0 \AA \\
90 \%\end{array}$ & 5 & 0.20 \\
\hline b) & & & $\mathrm{LM} 1$ & & & & & ILM 2 & & \\
\hline Saturation & $2 \mathrm{EG}$ & $1 \mathrm{EG}$ & $0 \mathrm{EG}$ & $\mathrm{N}$ & Ab. & $2 \mathrm{EG}$ & $1^{\mathrm{E}} \mathrm{G}$ & $0 \mathrm{EG}$ & $\mathrm{N}$ & $\mathrm{Ab}$. \\
\hline $\mathrm{Ca}$ & $\begin{array}{c}16.8 \AA \\
95 \%\end{array}$ & $\begin{array}{c}12.9 \AA \\
5 \%\end{array}$ & - & 6 & 1.00 & - & - & - & - & - \\
\hline $\mathrm{K}$ & $\begin{array}{c}16.9 \AA \\
15 \%\end{array}$ & $\begin{array}{c}13.9 \AA \\
60 \%\end{array}$ & $\begin{array}{c}10.0 \AA \\
25 \%\end{array}$ & 6 & 0.87 & $\begin{array}{c}16.9 \AA \\
10 \%\end{array}$ & - & $\begin{array}{c}10.0 \AA \\
90 \%\end{array}$ & 5 & 0.13 \\
\hline $\mathrm{K}-\mathrm{Ca}$ & $\begin{array}{c}16.9 \AA \\
70 \%\end{array}$ & - & $\begin{array}{c}10.0 \AA \\
30 \%\end{array}$ & 6 & 0.87 & $\begin{array}{c}16.9 \AA \\
20 \%\end{array}$ & - & $\begin{array}{c}10.0 \AA \\
80 \%\end{array}$ & 5 & 0.13 \\
\hline
\end{tabular}

Table 2. Composition of the smectitic minerals obtained by fitting the experimental XRD patterns (Fig. 3). MLM1 and MLM2 refer to the two populations of crystallites containing layers with contrasting contents of interlayer water or ethylene glycol. Layers with 2, 1 , and 0 water layers are referred to as $2 \mathrm{~W}, 1 \mathrm{~W}$, and $0 \mathrm{~W}$, respectively. Layers with 2, 1, and 0 ethylene glycol layers are referred to as 2EG, 1EG, and 0EG, respectively. For each population of crystallites, the thickness of these layers is indicated as well as their proportion. Only random interstratification was considered. $\mathrm{N}$ is the number of layers stacked coherently. Ab. is indicative of the relative abundance of the two populations of crystallites. $\mathbf{a}$, and $\mathbf{b}$ refer to the calculations made for the AD and the EG patterns, respectively. 


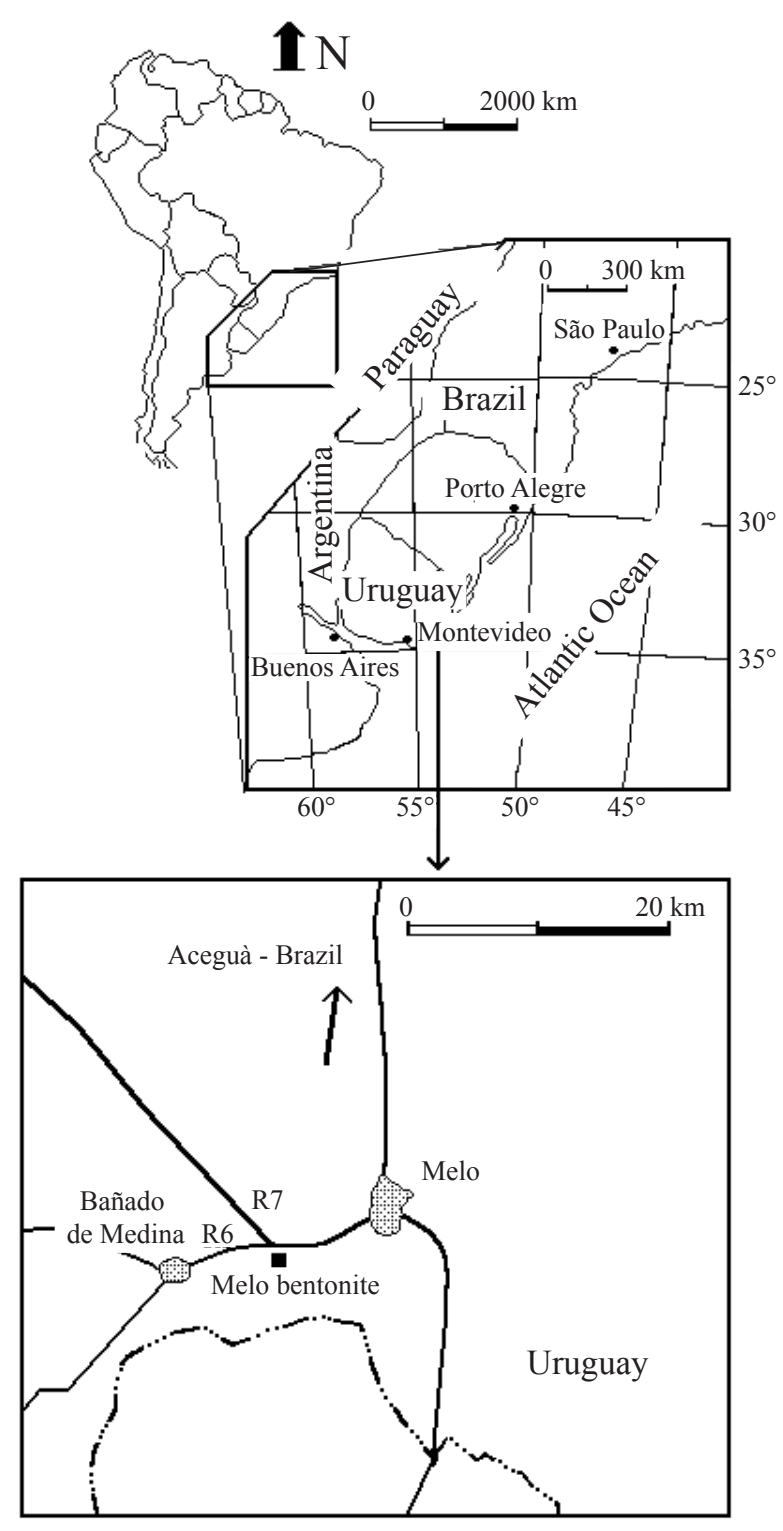

Calarge et al. fig. 1 


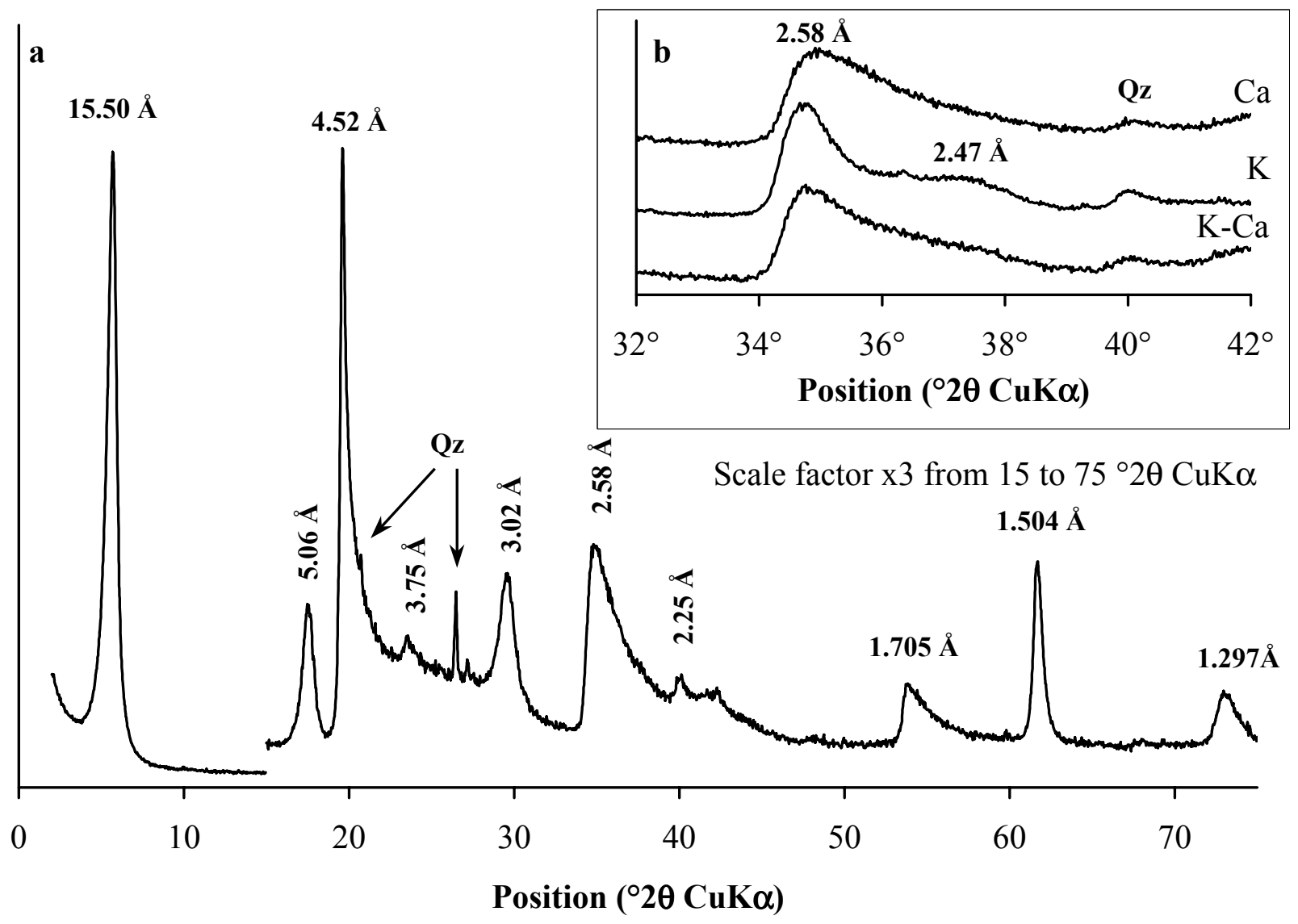

Calarge et al. fig. 2 

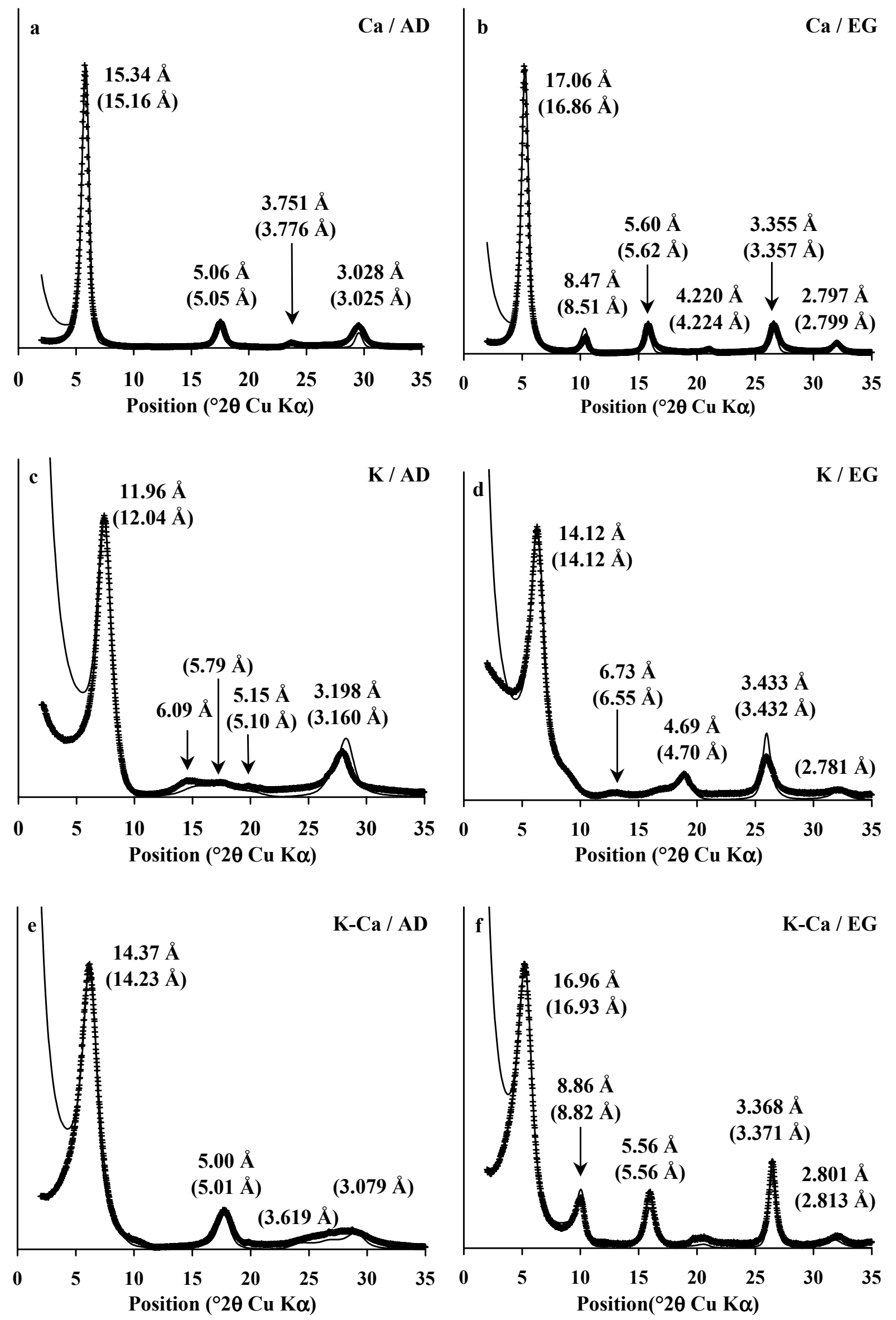

Calarge et al. fig. 3 


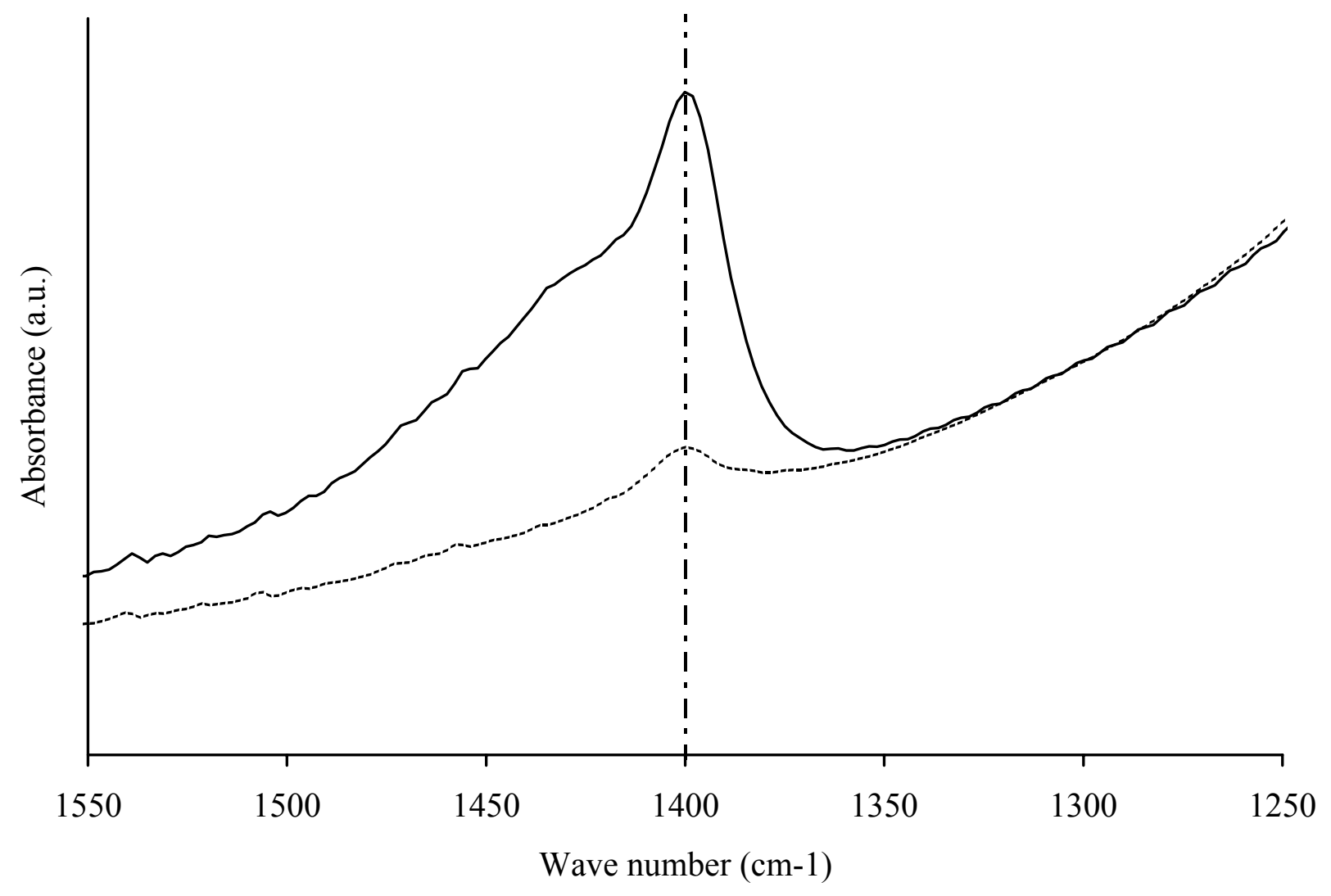

Calarge et al. fig. 4 

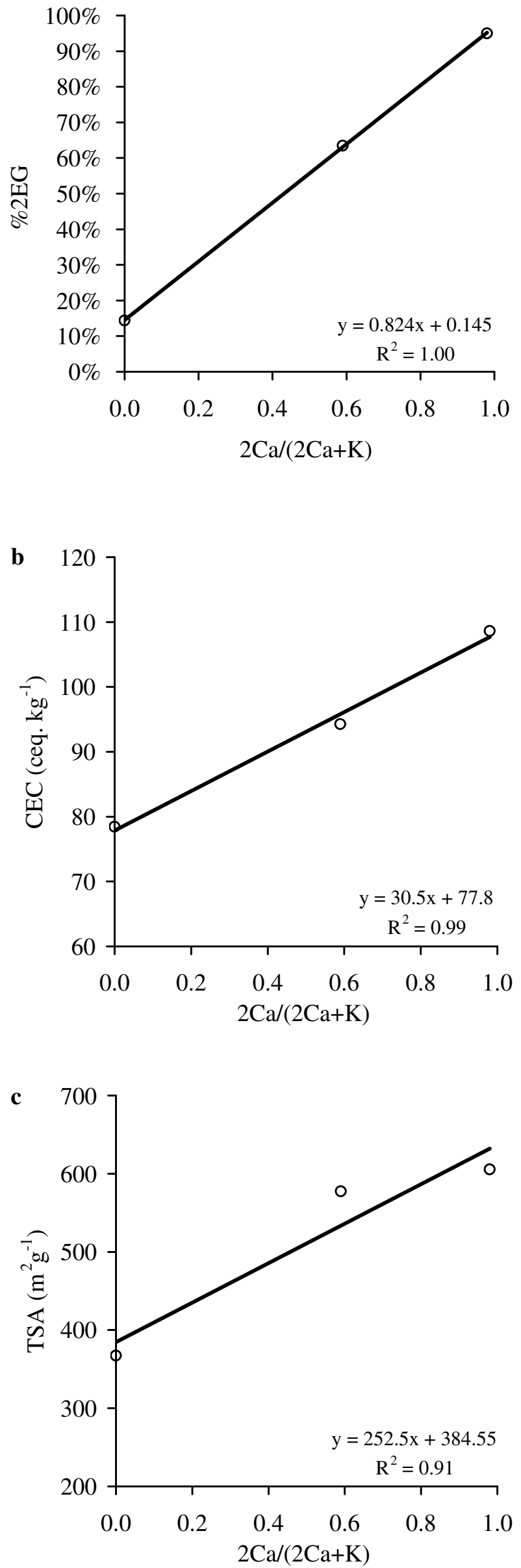

Calarge et al. fig. 5 